\title{
Evidence of tutoring in the development of subsong in newly-fledged Meyer's Parrots Poicephalus meyeri
}

\author{
SIMONE MASIN, RENATO MASSA and LUCIANA BOTTONI \\ Department of Environmental Sciences, University of Milano-Bicocca, Piazza della Scienza, 1, 20126 Milano, Italy
}

Manuscript received on January 15, 2004; accepted for publication on February 5, 2004.

\begin{abstract}
Subsongs are vocal trials uttered by young birds to practice songs. Among songbirds, subsongs are displayed by individuals in their first year of life. Studies on Zebra Finches Poephila guttata suggest that the juveniles learn their songs from a vocal tutor, their father. In this study we examine the subsongs in six captive-born Meyer's Parrots Poicephalus meyeri, from fledging time to weaning. Recordings of songs from chicks and fathers were analyzed for similarities in frequency and time parameters. With age, the subsongs of the chicks became more similar to the vocalizations of the fathers with $20 \%$ similarity rating in the first week after fledging to $100 \%$ at weaning time. Moreover, fledged chicks were exposed to a wide range of stimuli from several species of parrots breeding pairs caged nearby but chicks exclusively learned their fathers' songs. Our data support the hypothesis that Meyer's Parrots are vocal learners and use their father as their tutor.
\end{abstract}

Key words: subsong, notes, vocal tutor, Meyer's Parrot, Psittacidae.

\section{INTRODUCTION}

Young songbirds often emit subsongs while they are practicing and mastering their final song (Margoliash and Staicer 1991). In oscine songbirds, subsongs are emitted by newly-fledged and immature individuals in their first year of life (Baptista and Petrinovich 1984). In these birds, a closed-ended learning path was often reported, in that the full song displayed by sexually mature males remains almost crystallized as a stable song for the rest of their life. Many studies with Zebra Finches Poephila guttata indicate that adult males function as tutors (Böhner 1983, Mann and Slater 1994, Tchernikovski et al. 2001), boosting the song learning of the youngsters. In contrast, youngsters isolated from male tutors in the first 1-50 days of life show song learning problems and sing songs that are considered abnor-

Correspondence to: Simone Masin

E-mail: bioacust.lab@unimib.it mal. Moreover, age seems to be involved in song learning patterns of songbirds. For example, in the White-crowned Sparrows Zonotrichia leucophrys, fledglings learn appropriate songs from tape recordings of tutor songs or from live tutors when they are between 10-50 days old, but after 50 days, tape recorded songs are not effective and only live tutors can promote song learning (Marler 1970).

Surprisingly, even though much data are available on oscine birds song learning, information about parrot subsong development remains mostly anecdotal or limited to learning in Budgerigar Melopsittacus undulatus (Brown and Farabaugh 1988, Farabaugh et al. 1994). Budgerigars show great plasticity in song and call learning. Although song learning is common in oscine birds, learning of calls appears to be somewhat less common. In fact, such simple vocalizations were once thought to be innate (Thorpe 1961). Parrots, with their typical open-ended learning paths and the lack of a de- 
fined sensitive phase, could provide a new intriguing perspective on repertoire building strategies in birds (Brown et al. 1988). As Farabaugh et al. (1994) showed, even adult Budgerigars learn contact calls of new cage mates. After eight weeks of direct social interaction, birds from the same cage shared the same dominant contact call types, even though they initially emitted different calls. Moreover, call convergence through mutual vocal imitation was more pronounced among Budgerigars that could see, hear and interact with one another in the same enclosure compared to birds that were only allowed auditory contact.

The aim of this study was to examine the onset of subsong and the development of call repertoire in six captive-born, 4 parent-raised and 2 hand-raised, Meyer's Parrots Poicephalus meyeri. We were interested in whether studying the subsongs uttered by fledgling chicks could provide a clearer insight into the processes involved in vocal repertoire building in this species of African parrot. In particular, we wanted to understand if father utterances were of any importance for the development of subsong and if the 'father-as-tutor' hypothesis could be validated for a non-oscine bird. This is interesting because Psittaciformes and Passeriformes Oscines are highly derived taxa and vocal learning probably arose independently in these groups (Nottebohm 1972, Brauth and McHale 1988).

\section{MATERIALS AND METHODS}

We studied the vocalizations of a captive pair of Meyer's Parrots and their six chicks born during two subsequent breeding seasons. The breeding pair was kept in a large aviary ( $2 \mathrm{~m}$ length, $2.5 \mathrm{~m}$ height, $1 \mathrm{~m}$ width) at The Parrot Breeding and Research Centre of the University of Milan. The parrot enclosure was provided with wooden perches and standard Grey Parrot nest $(60 \mathrm{~cm}$ height, $40 \mathrm{~cm}$ length, $20 \mathrm{~cm}$ width, $10 \mathrm{~cm}$ access hole) simulating a hollow log to promote breeding activities. Balanced parrot chows (Versele Laga, Nutribird G14) and fresh fruit were available ad libitum. A small dark chamber was built adjacent to the short side of the enclosure to allow ethological data collection and audio recordings without disturbing animals breeding activities. The first breeding attempt produced 4 chicks (the younger two of them were taken at two weeks of age and hand-raised, originally in order to avoid starvation from competition among siblings), while in the following season only two chicks were fledged. Vocalizations of all chicks were recorded with a DAT recorder equipped with a directional microphone 4 times a day (06h30-08h30 am; 10h30-12h30 am; 02h30-04h30 pm; 06h30-08h30 pm), 4 days a week for 5 weeks (from fledging to complete weaning). An average of 50 subsong episodes were collected for each chick. Each subsong bout can include up to 4 themes, which can be divided into one, two or more notes. A total of 572 hours of ethological observations and recordings were performed. At the same time, random samples of 200 father vocalizations were recorded to allow comparisons of adult and juvenile repertoires. Vocalizations were analyzed on a Power Macintosh 7300/200 computer using Canary 1.2.4 software.

The hand-raised chicks from the first breeding season were maintained in a parrot brooding unit in the bioacoustic lab and fed with a commercial hand-rearing parrot feed until weaning. Consequently, they grew up without any acoustical input from conspecifics. Vocalizations of the hand-raised birds were recorded twice a day during feeding activities.

Acoustic measurements of juvenile and adult vocalizations were obtained from spectrograms. We isolated and classified the notes, i.e. minimal discrete units in subsongs defined as continuous tracks on spectrograms, in the vocalizations from each chick recorded each week. Spectrographic measurements allowed us to compare both frequency and time parameters in youngsters' subsongs and adult vocalizations. We obtained the frequency at which the highest amplitude in a selected area occurs (measured on fundamental and higher harmonics, $\left.P k_{f 0}, P k\right)$, the upper and lower frequency limits of the selected region (Fmin, Fmax), total length, pause length, the duration of single notes and the time gaps among notes. Data from chick vocaliza- 


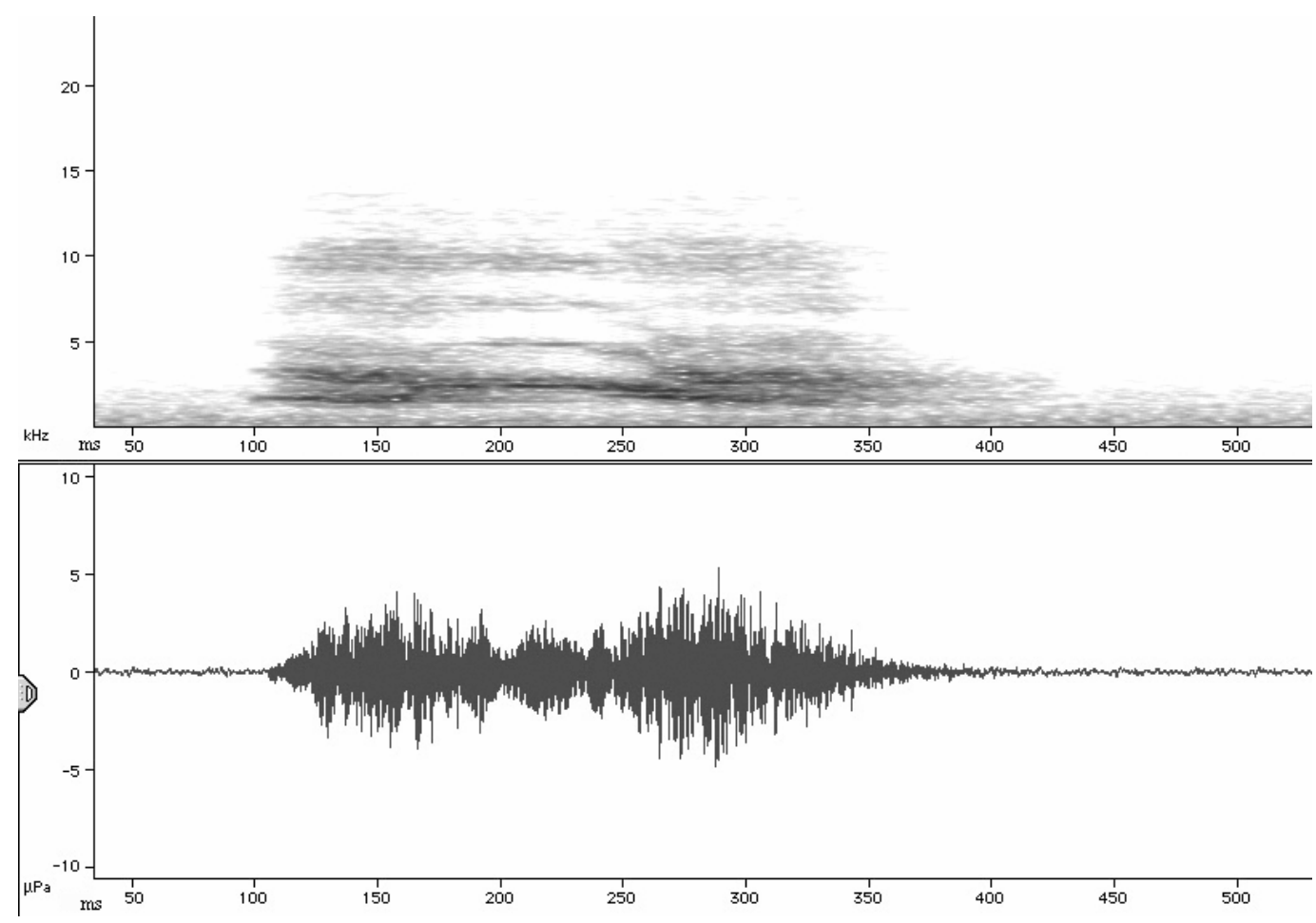

Fig. 1 - Spectrogram of father monosyllabic theme $\alpha$.

tions were classified by the number of notes and the age from fledging. Father utterances were divided according to note number in three groups: monosyllabic, disyllabic and trisyllabic themes. SPSS ANOVA tests, run on each category, pointed out the presence of 2 different monosyllabic, 2 different disyllabic and 1 trisyllabic vocalizations identified for both time and frequency parameters with high significance values.

Father themes were named with Greek letters from $\alpha$ to $\epsilon$. Tukey's Post Hoc tests at 95\% confidence interval amongst subsets allowed us to first identify the relevant parameters for theme discrimination, then to numerically compare father themes with chicks subsongs. Vocal development in chicks was represented by histograms. We classified every chick's vocalization (subsong) as similar to the parental one if the frequency and time parameters in the note/notes matched the confidence intervals for both frequency and time measurements in the adult vocalizations.

\section{RESULTS AND DISCUSSION}

\section{Adult vocalizations}

Five different vocalization themes were recorded and isolated from the adults. Two themes were monosyllabic, one sounding as a hoarse call $(\alpha$; Fig. 1), the other as a sweet chirp ( $\beta$; Fig. 2). Two themes were found to be disyllabic $(\gamma, \delta)$, one being similar to a double click, while the other one resemble a loud whistle. Only one theme appeared to be trisyllabic. This theme $(\epsilon)$ was frequently observed as a sort of father identity call; the male often uttered it when approaching the nest hole, possibly to inform the female about his identity.

\section{FIRST YEAR CHICKS P1 AND P2}

As shown in figure 3, the similarity percentages of the first two chicks show an increase from the first to the last week with the first theme present in subsongs being mostly monosyllabic $\beta$. Both chicks showed $20 \%$ similarity on the first week after fledging, sug- 


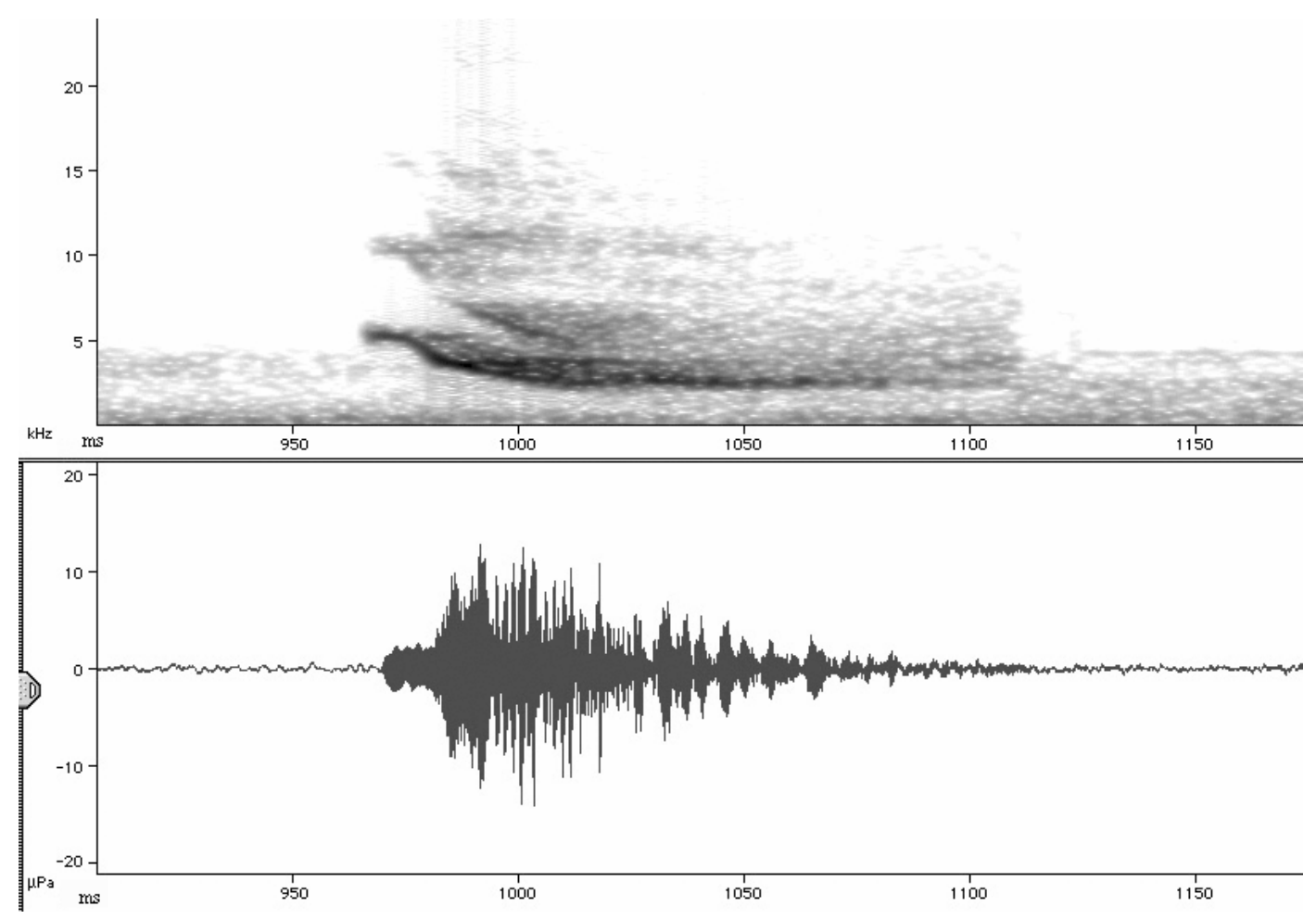

Fig. 2 - Spectrogram of father monosyllabic theme $\beta$.

gesting that vocal learning begins when chicks are still nestling. Some simple monosyllabic calls could have a signature whistle function allowing the earlyfledged chicks to enter the nest at nighttime and avoid the female's aggressions. The two chicks' subsongs matched $100 \%$ similarity with father themes at the fifth week.

\section{SECOND YeAR CHICKS P3 AND P4}

The two chicks from the second breeding season showed an even more distinct pattern in similarity percentages. Their themes were classified as superimposable with the father calls and lacked the falls that were present in the third and fourth week of the year 1 chicks. Once again, the year 2 chicks had $20 \%$ similarity in the first week after fledging, suggesting the importance of early vocal learning. These findings are similar to those found in development of vocal mimicry of Australian cockatoos (Rowley 1980, Rowley and Chapman 1986).

\section{HAND-RAISED CHICKS}

The two hand-raised chicks allowed us to make comparisons between individuals raised in a normal vocal and social context with chicks raised in an isolated environment without any other parrots. Comparing the vocalizations from these chicks with the father's themes resulted in no common features between vocalizations for the whole period of weaning. Subsongs recorded from these chicks revealed a simpler harmonic contour and a significantly higher repetition of notes compared to tutor-raised chicks (ANOVA significance $<0.005$ ) suggesting that the isolated chick calls were mainly modified begging calls and not subsongs.

\section{CONCLUSION}

Our results suggest that these parrots learn songs from tutors. The subsongs of the chicks increased in their similarity to adult songs over the course of a few weeks such that at weaning time every chick 

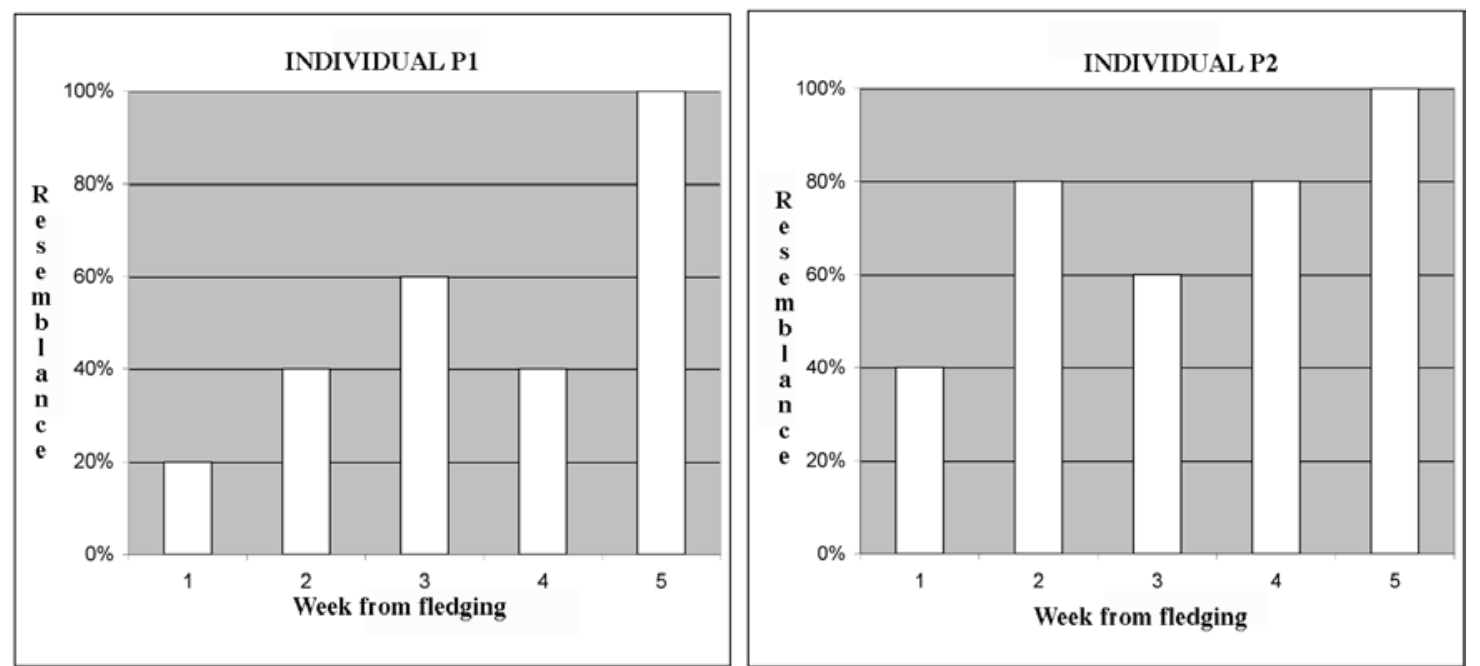

Fig. 3 - First season chicks subsongs similarity percentage with father themes, from nest emergence to complete weaning.
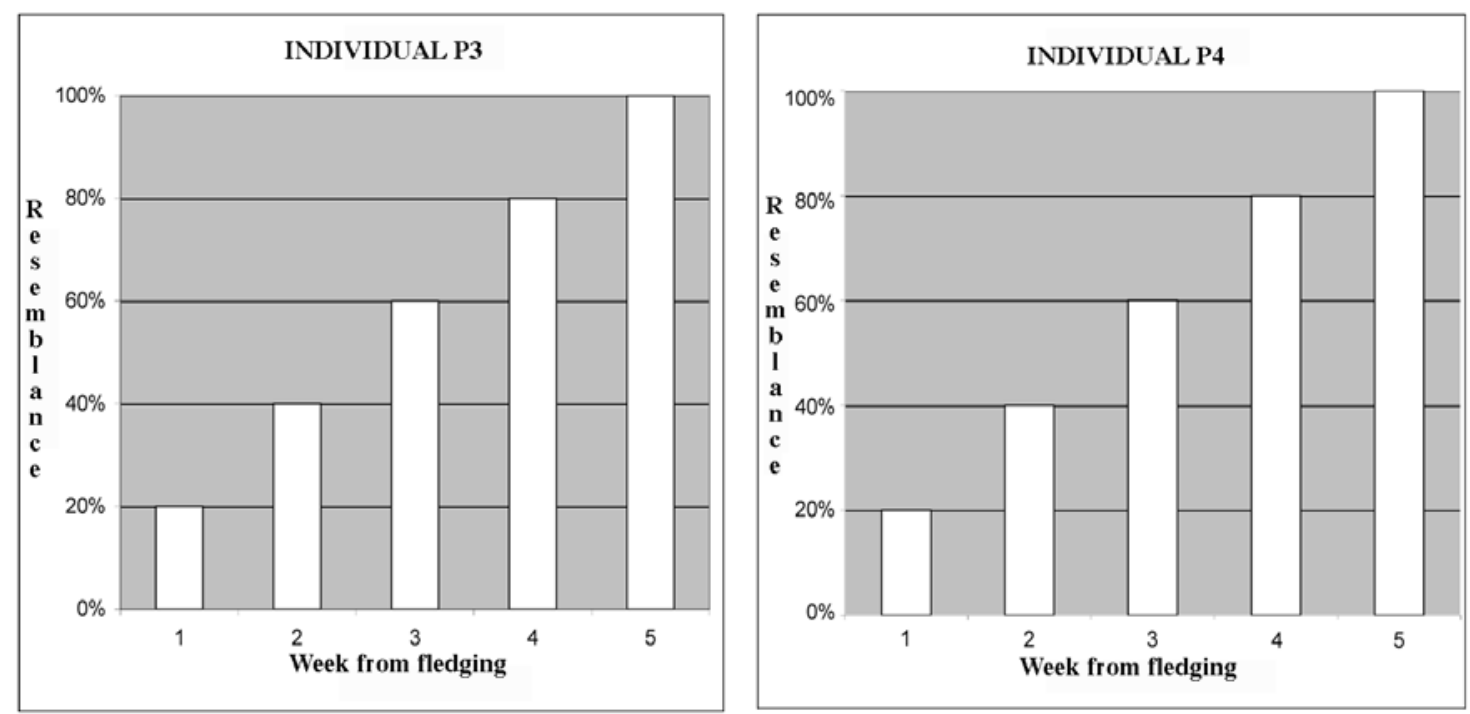

Fig. 4 - Second season chicks subsongs similarity percentage with father themes, from fledging to complete weaning.

showed a $100 \%$ similarity with father's vocalizations. Experimental evidence in passerine birds of many species stresses the importance of subsongs as vocal trials (Rowley 1980). Studies with Zebra Finches Poephila guttata (Dooling and Searcy 1980, Böhner 1983, Williams 1990) indicate that fledged chicks often choose their father as the vocal tutor over other adult males in the community. This suggests that the chicks can discriminate songs uttered by their father from those from other males. Al- though Meyer's Parrots are not a colony breeding species like Zebra Finches (Wagener et al. 1990), they gather their fledged chicks in nursery areas, and several juveniles from different breeding pairs can usually be found in one area. Thus, during song learning chicks in nursery areas are exposed to multiple inputs from several adult males. In our breeding center several breeding pairs are caged nearby, so fledged youngsters are able to hear and learn from several adult males. However, our results suggest 
that chicks choose their father as the vocal tutor, similar to the Zebra Finches (Tchernichovski et al. 2001). Moreover, chicks reared without a proper vocal context produced significantly different subsongs, with a simpler and monotonous melodic contour. These results further support the tutorial hypothesis in this species of parrot.

\section{RESUMO}

Os "subsongs" são ensaios vocais emitidos pelas aves jovens para exercitar suas vozes. Nos pássaros canoros, "subsongs" são exibidos por indivíduos em seu primeiro ano de vida. Estudos com Poephila guttata sugerem que os jovens aprendem seus cantos de um tutor vocal, seu pai. Neste trabalho examinamos os "subsongs" em seis papagaios Poicephalus meyeri nascidos em cativeiro, desde a saída do ninho até a emancipação. Gravações dos cantos dos filhotes e dos pais foram analisadas para medir as similaridades nos parâmetros de freqüência e tempo. Com a idade, os "subsongs" dos filhotes viraram mais semelhantes às vocalizações dos pais, com $20 \%$ de similaridade na primeira semana após a saída do ninho até $100 \%$ na hora da emancipação. Ademais, os filhotes foram expostos a uma grande variedade de estímulos de várias outras espécies de papagaios nidificando em gaiolas vizinhas, mas eles aprenderam somente os cantos de seus pais. Nossos dados confirmam a hipótese de que esta espécie de papagaio tem aprendizagem vocal e utilizam o pai como tutor.

Palavras-chave: "subsong", notas, tutor vocal, Poicephalus meyeri, Psittacidae.

\section{REFERENCES}

Baptista LF and Petrinovich L. 1984. Social interactions, sensitive phases and the song template hypothesis in the White-crowned Sparrow. Anim Behav 32: 172-181.

BöHner J. 1983. Song learning in the Zebra Finch (Taeniopygia guttata): selectivity in the choice of a tutor and accuracy of song copies. Anim Behav 31: 231237.

Brauth SE and McHale CM. 1988. Auditory pathways in the Budgerigar: II. Intratelencephalic pathways. Brain Behav Evol 32: 193-207.
Brown ED and Farabaugh SM. 1988. Song sharing in a group living songbirds, the Australian Magpie, Gymnorhina tibicen. Behaviour 104: 1-28.

Brown SD, Dooling RJ and O’Grady K. 1988. Perceptual organization of acoustic stimuli by Budgerigars (Melopsittacus undulatus): III. Contact calls. J Comp Psychol 102: 236-247.

Dooling RJ AND SEARCy WA. 1980. Early perceptual selectivity in the Swamp Sparrow. Develop Psychobiol 13: 499-506.

FARABAugh SM, Lizenbold A And Dooling RJ. 1994. Vocal plasticity in Budgerigars (Melopsittacus undulatus): evidence for social factors in the learning of contact calls. J Comp Psychol 108: 81-92.

Mann NJ and Slater PJB. 1994. What causes young male Zebra Finches, Taeniopygia guttata, to choose their father as song tutor? Anim Behav 47: 671-677.

Margoliash S and Staicer CA. 1991. Stereotyped and plastic sound in adult Indigo Bunting (Passerina cyanea). Anim Behav 42: 367-388.

MARLER P. 1970. A comparative approach to vocal learning: Song development in White-crowned Sparrows. J Comp Physiol Psychol 71: 1-25.

Noтteвонм F. 1972. The origins of vocal learning. Am Nat 106: 116-140.

Rowley I. 1980. Parent offspring recognition in a cockatoo, the Galah, Cacatua roseicapilla. Austral J Zool 28: 445-456.

Rowley I AND Chapman G. 1986. Cross-fostering, imprinting and learning in two sympatric species of cockatoo. Behaviour 96: 1-16.

TChernikovski O, Mitra P, Lints T And NotTebohm F. 2001. Dynamics of the vocal imitation process: how a Zebra Finch learns its song. Science 291: 2564-2569.

Thorpe WH. 1961. Bird song. London: Cambridge University Press.

Wagener T, Werner F and Lanterman G. 1990. Die Afrikanischen Großpapageien. Natur Verlag White.

Williams H. 1990. Models for song learning in the Zebra Finch: fathers or others? Anim Behav 39: 745-757. 